\title{
Glacier changes monitoring in Bhutan High Himalaya using remote sensing technology
}

\author{
Mithun Kumar ${ }^{1}$, Ayad M. Fadhil Al-Quraishi ${ }^{2^{\dagger}}$, Ismail Mondal ${ }^{3}$ \\ ${ }^{1}$ Space and Environment Research Center (SERC), Rajshahi-6205, Bangladesh \\ ${ }^{2}$ Department of Environmental Engineering, College of Engineering, Knowledge University, Erbil 44001, Kurdistan Region, Iraq \\ ${ }^{3}$ Department of Marine Science, University of Calcutta, India
}

\begin{abstract}
The primary objectives of this study are to identify glacier cover, detect changes of glacier from 1978 to 2017 in Bhutan, and identification of vulnerable zone based on glacier changes. Landsat images and remote sensing (RS) techniques, Maximum Likelihood Classification approach of Supervised Learning of image processing has been utilized to detect and monitor the glacier cover changes of Bhutan over the years (1978-2017) The study results revealed that total area of the glacier changes in 1978 and 2017 has decreased by 2.54\%. Most of the glacier zones are found in the northern part of the country, basically near the Greater Himalayan Mountain Range. Gasa, Bamthung and Lhuentse districts of Bhutan were found to have more glacier changes area than the other districts, that the areas experienced more changes of glacier cover over 40 years. Where more changes in the glacier are detected, the area should be more vulnerable in terms of both landslide, unreliability in growing useful land covers and Glacier Lakes Outburst Floods (GLOFS) in downstream area.
\end{abstract}

Keywords: Climate Change, Computer Vision, Glacier, Himalaya, Landsat, Supervised Classification

\section{Introduction}

Cryosphere is the portion of Earth surface where water is found in solid forms such as ice, glaciers, and permafrost. In winter, about $50 \%$ of land surface is covered with snow [1]. Even though the survival time of various types of snow cover is distinctive as like as the permanent snow cover is retained for many years, but impermanent and continuing snow covers do not endure in the summer time. Generally, the distribution of snow cover is different between two hemispheres. Southern hemisphere contains a huge permanent snow cover while the northern hemisphere contains a temporary and seasonal snow cover [2]. As one of an integral part of the climate systems snow covers influence and be subjective to effect on climate change [3]. It is very important to observe and monitor the components of cryosphere for a better understanding of the cryospheric and terrestrial climate system. Without a thorough analysis of cryospheric processes future state of the environment may not be predicted about, in particular the functioning of the climate system [1,3]. The Fourth Assessment Report of Intergovernmental Panel on Climate Change indicates that cli-

This is an Open Access article distributed under the terms of the Creative Commons Attribution Non-Commercial License (http://creativecommons.org/licenses/by-nc/3.0/) which permits unrestricted non-commercial use, distribution, and reproduction in any medium, provided the original work is properly cited.

Copyright (C) 2021 Korean Society of Environmental Engineers mate change will cause heavy damage of economic growth, and people will be vulnerable by the result of frequently visited hazards including, sea level rise, natural disasters, and tremendous weather actions such as storms, floods and droughts, shifts in growing seasons [4-7]. Because of highly reflective shortwave solar radiation, snow and ice provide a feedback mechanism to the system and annual long-term variation of their presence modifies the distribution and flow of water [2].

Mountain glaciers and ice cover in the Himalayas, significantly contribute to global sea level changes. The climate change and variability is depends on mass balance. In the study of Bajracharya et al. [8], they affirmed that the United Nations Environment Program (UNEP) conducted and recognized in their previous report about 15,000 glaciers (covering an area of 33,340 $\mathrm{km}^{2}$ ), and 9,000 glacial lakes all through Bhutan, Nepal and Pakistan, since some river basins in China and India. In recent past Nepalese territory were adversely affected by 21 glacial lake outburst floods (GLOFs), and that time 200 potentially risky lakes contain predictable crosswise the Himalayan mountain region. These were such dangerous events emphasize the emergency needs to increase systematic information

\footnotetext{
${ }^{\dagger}$ Corresponding author

Email: ayad.alquraishi@knu.edu.iq

Tel: +9647507641054

ORCID: 0000-0001-7732-129X
} 
of glacier environment by constantly accessing glaciers and glacial lakes, transport to susceptibility assessments, implementing alleviation and alteration mechanisms, and emergent a GLOF early-warning system. The Himalayan River basins are consequence of leftovers uncertain due to glacial melt. More than 70 million people could threaten food security to declining water availability. To monitor the glaciers and improve the cross-boundary scientific collaboration allows policy options on apposite scientific substantiation [9-10]. Negi et al. [11] emphasized in their study that snow monitoring is useful for hydrological modeling. The Hydrological modeling contributes melted excess at an exacting point of instance. Raup et al. [12] in their study explain that, it is very influential in mapping and monitoring the glacier, ice caps, and ice sheets that snow and ice are the extremely significant components of the Earth's natural system and human environment. Moreover, snow is very important due to its power to moderate extremes in hydrological cycles. They stated that melting of ice cover contributes to the rising of global sea level, whereas the snow and ice are the natural indicators of climate changes. Therefore, it is very essential to monitor the snow cover to expand an impression of it and set up a base for assess potential trend [1]. It is very important to assess the trend, rate, location, nature and magnitude of ice cover changes that occurred in the area under investigation.

Ground monitoring of snow and ice could be very accurate, but that is suitable for limited area. It is inaccessible to direct observation to map high-altitude mountain glaciers. In general, to monitor the snow and ice of a vast and inaccessible area like Southern Himalaya, specifically Bhutan, remote sensing (RS) technology is always a better option; due to its capability to produce significant results with acceptable accuracy at a low cost. The RS and Geographical Information System application is mostly useful for remote areas in concurrence with field-based measurement of glaciological modeling [13-19]. Veettil et al. [20] explained in their study, it was difficult to map debris-covered glaciers using visible and infrared imagery, unlike the other types of glaciers. In the study, the supra-glacial/ice-cold debris cover was mapping by Landsat MSS, TM, ETM+ and OLI images, as well as using the digital elevation model (DEM) dataset. There is a need for high-resolution images to combine with field-based work data, and exterior ablation signature to make significant maps of glaciers. RS is employed as a rule based method for monitoring trend of changing the glaciers incorporating optical, radar, and DEM in worldwide [20].

The economy of Bhutan depends on tourism, hydro-power and agriculture, while these sectors directly and indirectly depend on its water resources comes from glaciers [3]. Therefore, it is highly essential to conduct a comprehensive study of the glaciers, its changes and impacts in a regular basis. The primary objective of this study is to identify and map the glacier cover and its changes over a span of 40 years (1978-2017) in Bhutan from space-borne satellite. Vulnerable zone identification and mapping are additional objectives of this study. This study is very effective to provide an access to in sequence of policy makers, scientists, and general people at huge in the area and afar of this area.

\section{Material and Methods}

\subsection{Study Area}

The eastern Himalayas southern zone is located in Bhutan, which extend up to China, northern site of Sikkim, Assam, Arunachal Pradesh and West Bengal of northern part. The geographical extend up to latitudes $26^{\circ}-29^{\circ} \mathrm{N}$, and longitudes $88^{\circ}-93^{\circ} \mathrm{E}$ (Fig. 1). The Bhutan land is a high altitude mountainous zone, with elevation varies from $200 \mathrm{~m}$ to $7,000 \mathrm{~m}$ is crisscrossed irregular river valley prior to tough into the Indian plains. Bhutan is a richest country in terms of water resources and biodiversity [3]. The Northern site of the study area is consists of Eastern Himalayan shrubs, meadows and alpine to glaciated mountain peak. It characterized by cold climatic and high altitude elevations, and the total area are covered $38,394 \mathrm{~km}^{2}$. The study area extends up to $300 \mathrm{~km}$ from East to West, while North to South are extend $170 \mathrm{~km}$.

\subsection{Data Collection}

\subsubsection{Satellite data acquisition}

In this study, remotely sensed dataset from Landsat satellites ac-

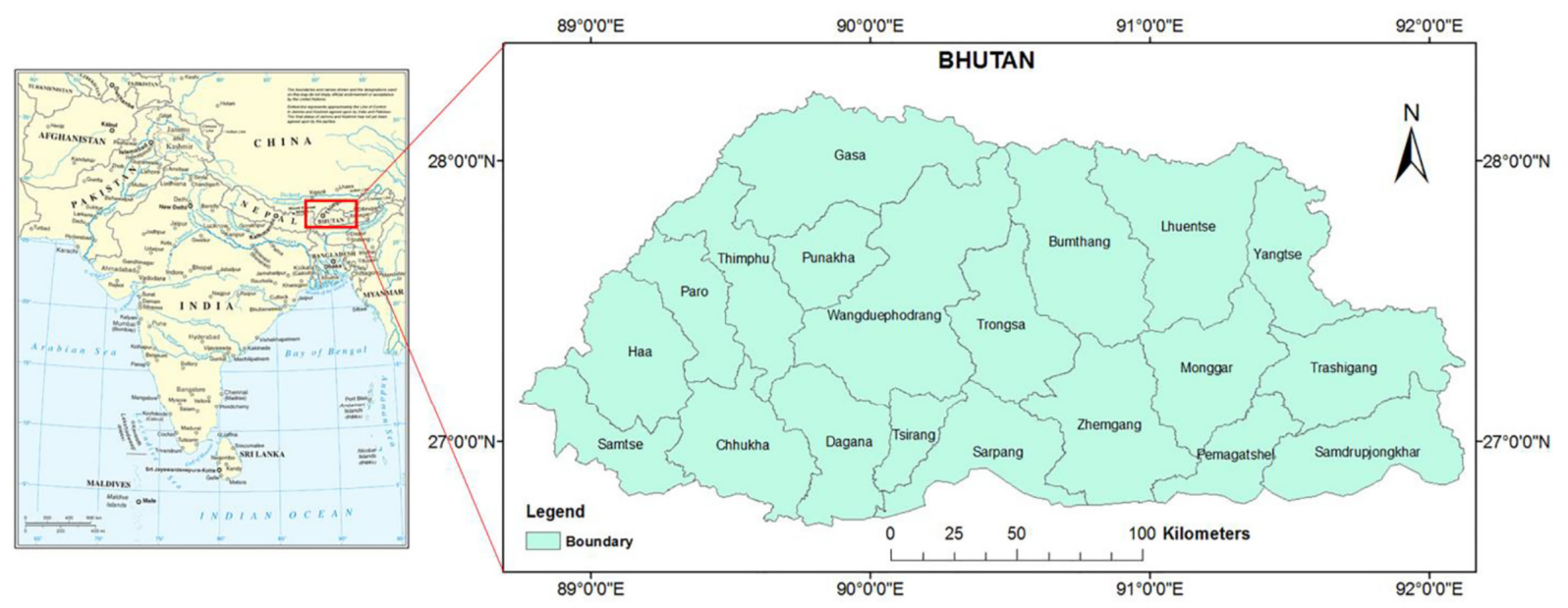

Fig. 1. Location map of the study area. 
Table 1. Details of the Landsat Satellite Images of the Years 1978, 2000 and 2017 Acquired by MSS, ETM+ and OLI, Respectively (Source: USGS, 2018 and Global Land Cover Facilities, 2013)

\begin{tabular}{cccccccc}
\hline Year & Frame No. & Satellite ID & Path/Row & Projection System & $\begin{array}{c}\text { Acquisition Date } \\
\text { (Day/Month/Year) }\end{array}$ & Spatial Resolution \\
\hline \multirow{2}{*}{1978} & $1^{\text {st }}$ & Landsat 2 (MSS) & $149 / 41$ & UTM within Zone 45N Datum & $23 / 01 / 1977$ & $60 \mathrm{~m}$ \\
& $2^{\text {nd }}$ & Landsat 2 (MSS) & $148 / 41$ & UTM within Zone 46N Datum & $07 / 12 / 1978$ & $60 \mathrm{~m}$ \\
& $3^{\text {rd }}$ & Landsat 2 (MSS) & $147 / 41$ & UTM within Zone 46N Datum & $24 / 12 / 1978$ & $60 \mathrm{~m}$ \\
\hline \multirow{2}{*}{2000} & $1^{\text {st }}$ & Landsat ETM+ & $139 / 41$ & UTM within Zone 45N Datum & $26 / 12 / 2000$ & $30 \mathrm{~m}$ \\
& $2^{\text {nd }}$ & Landsat ETM+ & $138 / 41$ & UTM within Zone 45N Datum & $20 / 11 / 2001$ & $30 \mathrm{~m}$ \\
& $3^{\text {rd }}$ & Landsat ETM+ & $137 / 41$ & UTM within Zone 46N Datum & $28 / 12 / 2000$ & $30 \mathrm{~m}$ \\
\hline \multirow{2}{*}{2017} & $4^{\text {th }}$ & Landsat ETM+ & $138 / 40$ & UTM within Zone 46N Datum & $17 / 11 / 2000$ & $15 / 01 / 2017$ & $30 \mathrm{~m}$ \\
& $1^{\text {st }}$ & $2^{\text {nd }}$ & OLI & $139 / 41$ & UTM within Zone 45N Datum & $24 / 01 / 2017$ & $30 \mathrm{~m}$ \\
\hline
\end{tabular}

quired by the MSS, ETM+ and OLI sensors for 1978, 2000 and 2017 series (Table 1), with spatial resolution of $60 \mathrm{~m}$ and $30 \mathrm{~m}$ were used for glacier cover assessment. The Landsat images were acquired during the winter months (Nov., Dec., Jan. of the years 1978, 2000, and 2017), whereas Table 1 shows their path/row, sensors, and the acquisition dates. The study area was not covered by one single frame or scene; consequently, several scenes have been mosaicked to get the total study area. The images for this study have been assembled and downloaded from the official websites of the GLCF, Maryland University [21] and the Global Visualization Viewer (GloVis) of the United States Geological Survey USGS [22]. A mosaicking and subscene clipping processes were done for the downloaded images to form the study scene for each date of study years.

For the purpose of ground information, two base maps of Bhutan for the years of 1975 and 2000 have been obtained from the Regional Database System of International Center for Integrated Mountain Development (ICIMOD) [23]. Google Earth was the available option to get the required ground information of the study area for the year of 2017. These reference data have been utilized during signature development for image processing and accuracy assessment of the final land cover maps.

\subsection{Data Processing and Analysis}

\subsubsection{Base map preparation}

For this study, a supervised maximum likelihood classification approach has been used to prepare a base map. Supervised classification is very effective and common technique for getting better land change detection [24]. Total image processing was done by using IDRISI Selva 17.0 and ArcGIS 10.2 software.

\subsubsection{Training site development}

The areas defined for each land cover type within the image are called training sites. False color composite of 4, 5, and 7 bands (RGB754) for the images of 1978 and 3, 2, and 4 bands (RGB423) for the images of 2000 and 2017 were generated and used for digitizing polygons around each training site for similar land cover. Then a unique identifier has been assigned to each known land cover type. The training sites have been developed based on collected base map, Google Earth data and auxiliary information.

\subsubsection{Spectral signature development}

The spectral signature of each land cover was created in this stage. The statistical characterization of each of land cover classes are needed after finishing the digitization of training sites. These are called spectral signatures and by analyzing of the pixel size signature, development is completed [25].

\subsubsection{Image classification}

In the studies that utilized satellite image processing, the more important point are the spatial resolution of the satellites images, plus the temporal resolution. The lower spatial resolution image (even up to $1 \mathrm{~km}$ ) has limited capability to view the land cover features. Therefore, the higher spatial resolution images can be better to be separate different features more efficiently. Temporal resolution could give better situation in testing time series analysis. The Maximum Likelihood Classification approach of the Supervised Classification algorithm has been adopted to classify the Landsat images for detecting and monitoring the glacier cover changes. The total area of each ice cover class was calculated for each of the three dates of the study, and then the post classification comparison method was employed to calculate the ice cover area changes.

A classification scheme was developed for further analysis of the study images, based on the characteristics of the area (Table S1), which is needed to identify ice cover in the study area. After image classification, ice cover area was extracted for further analysis and reporting.

\subsubsection{Generalization}

Sometimes many isolated pixels may found after image classification, whereas these pixels may belong to one or more classes that differ from surrounding classes. Therefore, filtering is used to generalize the images and remove the pixels [24]. A 3 x 3 mode filter has been applied to generalize the classified land cover images. After that final version of land cover maps of 1978, 2000 and 2017 were produced for results analysis (Fig. S1-S3).

\subsubsection{Accuracy assessment}

Accuracy assessment is a necessary stage of image classification process. Since, it is not typical to ground truth every pixel of the classified images, therefore some reference pixels are generated. Some points within the classified image are randomly selected 
to list two sets of class. The first set of class value represents the land cover type in the map, while the second set class values are known as reference values [24]. These reference values are input based on the ground truth data. Therefore, 160, 107 and 105 references values have been generated for the study classified images of the years 1978, 2000 and 2017, respectively to perform the accuracy assessment (Table S2-S4). In this study, two land cover maps of 1975 and 2000 obtained from the Regional Database System of International Center for Integrated Mountain Development (ICIMOD) [RDS] were wielded to make reference values for the accuracy assessment of the produced land cover map of 1978 and 2000. For the accuracy assessment of the produced land cover map of 2017, reference values were collected from a high resolution Google Earth image of the year 2016. It is a good option to verify the classified image in high resolution Google Earth images [26]. The gathered data was summarized and quantified by using error matrix. Four different accuracy results; user accuracy, producer accuracy, overall accuracy and Kappa Coefficient were produced from the overall assessment to which help to understand the accuracy of the classification [27].

\subsubsection{User's producer's and overall accuracy}

If the category is $\mathrm{K}$ in map then the user's accuracy for category $\mathrm{K}$ is the percent of category $\mathrm{K}$ in the reference information. The category K percentage in the map is the producer's accuracy for the category $\mathrm{K}$, given that reference information shows category $\mathrm{K}$ [24]. The producer's and User's accuracy are for all the years are found ranging approximately from $0 \%$ to $100 \%$ (Table S2-S4).

The overall accuracy represents the percentage of correctly classified pixels. It is gained by dividing the number of correct observations by the number of actual observation. The overall accuracy for 1978, 2000 and 2017 are found 80\%, 67.28\% and 71.42\%, respectively, when Kappa Coefficient results are 70.50\%, 50.47\% and $55.49 \%$, respectively derived from (Table S2-S4). However, overall accuracy and Kappa Coefficient is low but this classification was accepted for analysis. The primary focus of this study is to find out ice cover zone in the study site to detect the changes over the years 1978-2017. The results revealed that the user accuracy results of ice cover were $89.23 \%, 77.27 \%$ and $95.55 \%$, respectively, which are an acceptable result for the image classification analysis.

\subsubsection{Limitations in the base map preparation and accuracy assess-} ment

Finally, it can be observed that few misclassifications were in the classified land cover maps of the study area. The reasons may be as follows:

i) Some land cover types have the same spectral characteristics, thus in most cases, it is difficult to separate water bodies and low/cultivable land categories. The reasons behind that may be attributed to the seasonal variations of the satellite images for different years and similar spectral signatures of land covers in some cases. For example, to prepare data (for the year 2000) for image processing frames/scenes of Landsat ETM+ are used for mosaicking. In similar way, three frames/scenes of Landsat MSS and Landsat 8 are used for the same process to prepare the required data (for the year 1978 and 2017) for image processing of the study area. In both cases, all the frame/scenes are acquired in different time frame (Table 1).

ii) Moreover, spectral mixing of different land cover types is directed by less spectral resolution [24].

iii) Additionally, we should consider the spatial resolution of satellite images. The Landsat satellite images have been used for this research purpose that are only commercially available, but can be found in free public-domain. The spatial resolution of Landsat image (1978) is $60 \mathrm{~m}$ and $30 \mathrm{~m}$ for the images of 2000 and 2017, that are low resolution, which is the main problem in working with Landsat images. It can be much better option to use IKONOS, QuickBird or other satellite images with higher spatial resolution.

iv) Again, the collection of reference data or maps for ground truth purpose was the next limitation. The base maps of the years 1978, 2000 and 2017 have been prepared from Landsat satellite images. The reference data or maps are necessary for ground truth purpose of the base maps. It cannot measure the past with the present. To collect reference points for ground trothing of the base maps; both infield and outfield accuracy assessment is necessary, but it was not possible to collect reference point by Global Positioning System (GPS) visiting directly to the study site. So, in this case, secondary data have been employed for this purpose. The reference maps of land cover in the years of 1975 and 2000 have been collected from the Regional Database System of International Center for Integrated Mountain Development (ICIMOD) [23] for accuracy assessment of the base map of 1978 and 2000. Therefore, in this regard we had to depend on their accuracy. Additionally, the reference data to assess the accuracy of the base map in the year 2017 have been collected from Google Earth (acquisition year 2016). This may create some false understanding of the classification.

v) Since this study focus only upon the glacier, so there was given less importance in other land cover classes of the study area. It may cause few misclassifications of the study site.

If the aforementioned limitations can be reduced then overall accuracy and Kappa coefficient can be succeeded.

\section{Results and Discussion}

Three base maps were developed by processing of Landsat images for the years 1978, 2000 and 2017 to visualize and analyze of the land cover scenario of Bhutan (Fig. S1-S3). From the study results, it can easily understand that only the northern parts of the country are covered with ice, while the southern parts are covered with mostly vegetation and other land covers. Furthermore, from the measurements it was found the ice covered area in 1978, 2000 and 2017 are 4.06\%, 1.35\% and 1.52\%, respectively. Moreover, among the twenty districts in Bhutan, the districts located in the northern parts of Bhutan are mostly ice covered area (Fig. S4-S6). The Gasa, Lhuentse, Bamthung, Trahiyantse and Wangduphodang districts are located at the northern parts of the country (Fig. 1) containing the large amounts of ice covered area than the other districts. Total ice covered area has been decreased in 2000, and vegetation cover area has been increased over the years 1978-2000 (Fig. S3). The amount of difference between ice cover in 1978 


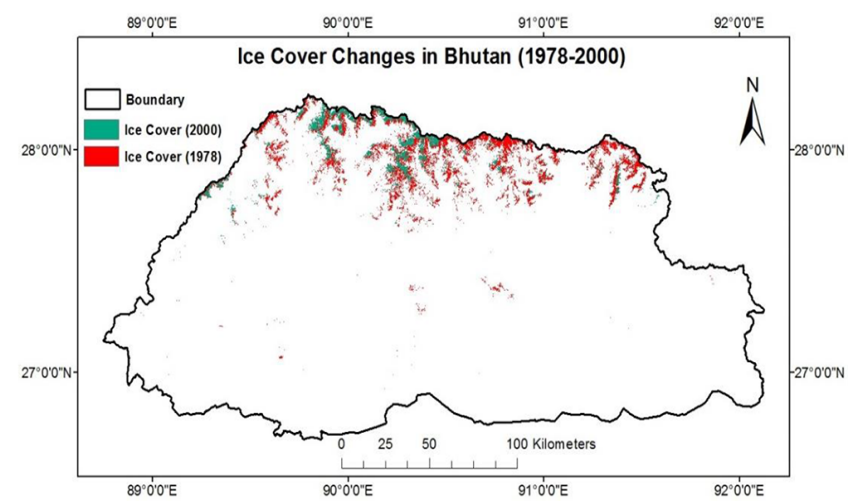

Fig. 2. Ice cover changes in Bhutan (1978-2000).

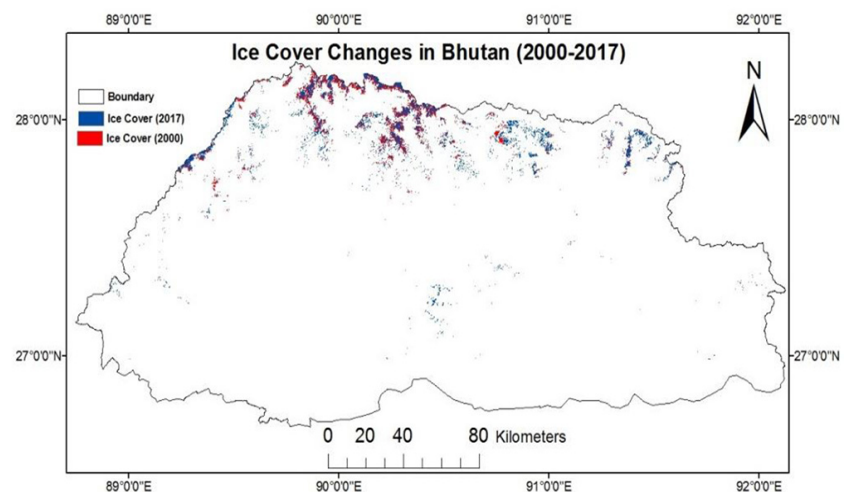

Fig. 3. Ice cover changes in Bhutan (2000-2017). and 2000 is (-2.71\%) (see Table S5). A significant change has been happened in the study area over 22 years (Fig. 2). Surprisingly, the amount of ice cover in 2017 has been increased a little bit ( $0.17 \%$ of the total area; see Table S6) based on 2000 (Fig. 3). Overall, 2.54\% (Table S7) of ice cover has been decreased by 2017 over 40 years span (1978-2017). Furthermore, it was found that four districts (Pemagatshel, Mongar, Shemgang and Sarpang) have no ice cover, but they have a large amount of vegetation comparatively to others. Gasa is the largest district of Bhutan with area contained $4,810.84 \mathrm{~km}^{2}$, whereas it contains the largest amount of ice cover (19.75\% of total area of Gasa in 1978). Results revealed that maximum districts remained stable in ice cover changes. Interestingly, about seven of them faced with a little bit positive changes (Table 2), mean it was found ice cover in some of the districts where was not been covered with ice in past. It was clear that a large amount of glacier has been lost in Gasa, Lhuentse, Bamthung and Wangphodang districts over 40 years (Table 2). Moreover, from the Fig. 4, it can be observed that the areas of ice cover have been basically changed the lower position of their past position. It is a clear indication that the glacier of Bhutan high Himalaya has been retreating over the years (Fig. 4). Finally, it was found that the change of ice cover in Bhutan is negative, that means the glacier of Himalaya has been decreased over the years and the trend of decreasing is upward. The region where ice cover changing is very high (negative or positive) is a vulnerable place, due to two types of changes, significantly effect on environmental system as like as the hydrological cycle, land-atmosphere interaction, ecology, etc. The zones of glacier change (Fig 5) have

Table 2. Amount of Differences in each Distract of Bhutan over 40 Years (1978-2017)

[The percentages represent the amount of ice cover of the total area of each district.]

\begin{tabular}{|c|c|c|c|c|c|c|}
\hline District & $\begin{array}{c}\text { 1978_Ice Cover } \\
(\%)\end{array}$ & $\begin{array}{c}2000 \_ \text {Ice Cover } \\
(\%)\end{array}$ & $\begin{array}{l}\text { 2017_ Ice Cover } \\
\text { (\%) }\end{array}$ & $\begin{array}{c}\text { Changes in } 2000 \\
\text { based on } 1978\end{array}$ & $\begin{array}{c}\text { Changes in } 2017 \\
\text { based on } 2000\end{array}$ & $\begin{array}{c}\text { Changes in } 2017 \\
\text { based on } 1978\end{array}$ \\
\hline Samdrup jankhar & 0 & 0.00 & 0.02 & 0.00 & +0.02 & +0.02 \\
\hline Tashigang & 0.05 & 0.02 & 0.11 & -0.03 & +0.09 & +0.06 \\
\hline Pemagatshel & 0.01 & 0.00 & 0.00 & -0.01 & 0.00 & -0.01 \\
\hline Mongar & 0 & 0.00 & 0.01 & 0.00 & +0.01 & +0.01 \\
\hline Zhemgang & 0.26 & 0.00 & 0.08 & -0.26 & +0.08 & -0.18 \\
\hline Sarpang & 0 & 0.03 & 0.15 & +0.03 & +0.12 & +0.15 \\
\hline Lhuentshe & 10.14 & 0.89 & 3.30 & -9.25 & +2.41 & -6.84 \\
\hline Bamthung & 8.23 & 1.16 & 1.80 & -7.07 & +0.64 & -6.43 \\
\hline Chhukha & 0.13 & 0.00 & 0.00 & -0.13 & 0.00 & -0.13 \\
\hline Daga & 0 & 0.00 & 0.00 & 0.00 & 0.00 & 0 \\
\hline Samtse & 0.01 & 0.00 & 0.00 & -0.01 & 0.00 & -0.01 \\
\hline Наа & 0.05 & 0.00 & 0.39 & -0.05 & +0.39 & +0.34 \\
\hline Paro & 0.14 & 0.36 & 0.39 & +0.22 & +0.03 & +0.25 \\
\hline Thimpu & 2.91 & 1.80 & 2.28 & -1.11 & +0.48 & -0.63 \\
\hline Gasa & 19.75 & 10.52 & 8.54 & -9.23 & -1.98 & -11.21 \\
\hline Punakha & 0.68 & 0.00 & 0.16 & -0.68 & +0.16 & -0.52 \\
\hline Tsirang & 0 & 0.08 & 0.00 & +0.08 & -0.08 & 0 \\
\hline Tongsa & 0.65 & 0.00 & 0.75 & -0.65 & +0.75 & +0.1 \\
\hline Wangduphodang & 6.4 & 1.97 & 1.67 & -4.43 & -0.30 & -4.73 \\
\hline Trashiyangtse & 5.72 & 1.91 & 3.89 & -3.81 & +1.98 & -1.83 \\
\hline
\end{tabular}




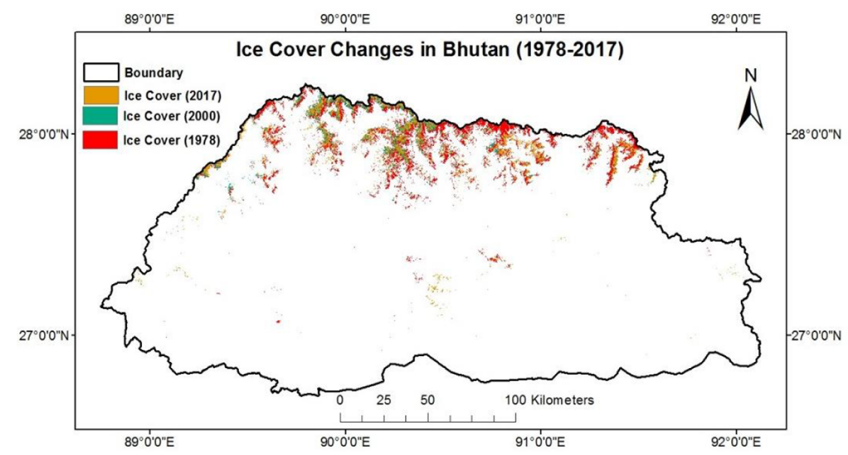

Fig. 4. Ice cover changes in Bhutan (1978-2017).

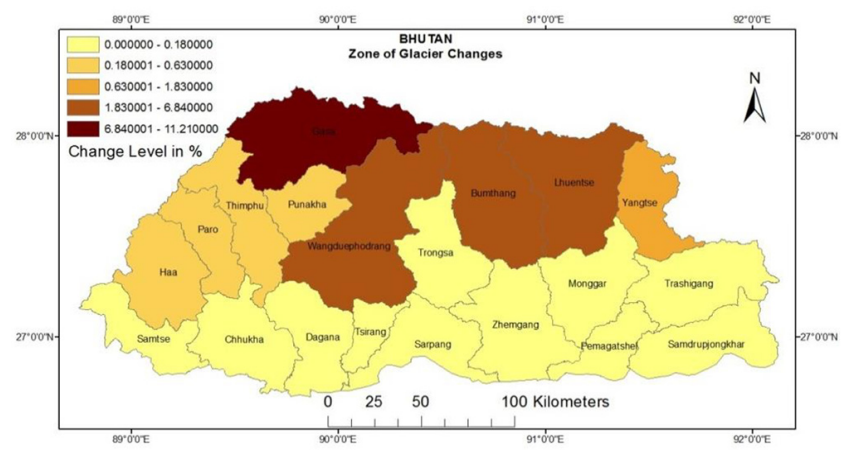

Fig. 5. Zone of glacier changes in Bhutan.

been identified by processing of Landsat satellites dataset. Vulnerability can be analyzed based on different factors. In this study, vulnerability was analyzed based on the ice cover change level.

RS provides baseline information on extension, aspect, slope, elevation, and type of glaciers, while to fully understand the prospective future challenges for glacier melt-water resources and glacial hazards complete inventories for different time series are effective [3, 26]. Basically, Bhutan is a country in the Hindu-Kush Himalayan region owing to the high altitude, remoteness of the terrain, and extreme climatic conditions containing a large number of glaciers. The condition of the glaciers of this area is a hot topic, because of their rapid melting and retreating. Mountain ice retreating and losing are critical issues, because the maximum of the rivers are created from the mountain ice and both Bhutan and other South-East Asian countries located in downstream area mostly depend on the water reservoir of Himalayan glacier. RS-based comprehensive assessment of the current status and observing the changes of glaciers in this area is very effective [26, 28]. For the better assessment, all the Landsat images were taken in consideration about same season and that was winter (December and January), and the reason behind that, generally glaciers are mostly formed and compacted in winter season. After processing the Landsat images of the years 1978, 2000 and 2017 we found the user accuracy results of ice cover class are $89.23 \%, 77.27 \%$ and $95.55 \%$, respectively. Since ice cover class accuracy is high, therefore these classifications were accepted for the analysis purposes. Most glaciers can be visible as clean-ice, but some parts of the glaciers mostly the down position of the glaciers contain debris cover [26]. Since this is a snow covered area, therefore, during training site development investigators should be more careful, otherwise there may be a misunderstanding during training site development in image processing happening misclassification of cloud as glacier cover and soil cover associated with debris cover may create problems to the eye of the analysts.

The ice cover changes of Bhutan are not equal in every districts of Bhutan. Essentially, this country is a hilly region and its topography is not even. Topographic features, such as altitude, aspect, and slope, play a key role in snow distribution [31]. Glaciers changes happen particularly in glacier tongue [26]. During this investigation, surprisingly, it was noticed that a little bit $(0.17 \%$ of the total area) glacier covered area was increased in 2017 from 2000. Fig. 3 shows that some parts of the study area were found with glacier cover in 2017, while in 2000 those areas were glacier free. This happened in between above $27^{\circ}$ and $27.5^{\circ} \mathrm{N}$ latitude and in between $90^{\circ}$ and $91^{\circ} \mathrm{E}$ longitude of the study area. Same thing was found in $28^{\circ} \mathrm{N}$ area (both above and below). It was found that the glacier covered area had lost ice cover from its tongue- the lower positions and stored some of the parts of the study area during winter where was not been covered with ice in past. However, a slight increasing of ice cover was found in 2017 based on 2000 overall findings indicate that the glacier covered area of Bhutan has been decreased in 2017 based on 1978 (Fig. 4). A large number (2.54\% of total area) of glaciers cover were lost by 40 years (1978-2017). Debris free glaciers are highly sensitive to climate changes. The glacier cover change is happening due to different factors, particularly due to global warming and climate change [3, 11, 26, 28-30].

Gasa, Bumthang, Lhuentse and Wanduepodrang districts contain a large amount of debris free glaciers and these four districts were experienced a large number of glacier cover lost where others districts have not found more significance changes. Among these four districts, Gasa is larger than others containing a large portion of glacier have been lost $11.21 \%$ of glacier cover of the total area of this district. Bumthang and Lhuentse districts lose $6.43 \%$ and $6.84 \%$ of glacier cover of their total area (Table 2). Fig. 5 shows the glacier-changing zone. Vulnerable zone of glacier changes was found in between about $27.5^{\circ} \mathrm{N}$ latitude and about $28.5^{\circ} \mathrm{N}$ latitude. This area contains large amount of glacier and experienced its changes over the 40 years. It is very important to assess both positive and negative changes of glaciers, and take necessary measuring steps because both rapid changes results land slide, GLOFs events and other natural hazards [3]. Consequently, the people and property living on downstream area will be face with dangerous impacts. Glacier melt and snow melt are complex energy-balance processes, which are influenced by debris cover, black carbon deposition, albedo feedback, and sublimation [26].

\section{Conclusions}

This research has revealed decreasing of the ice cover in Bhutan over 40 years (1978-2017). Latter our paper has presented the "Maximum Likelihood Classification" approach of supervised learning of image processing for Landsat image classification to identify and map the ice covered area of the study area. Landsat images of different spatial and temporal resolution were utilized for ice 
cover detection, but the images with higher spatial resolution can provide better accuracy. In general, the findings of this study show that Bhutan contains large amounts of glacier at the northern part of the country at the foothills of the Great Himalayan Mountain. Moreover, this study presents the rate of ice cover changes; i.e. due to climate change, water resource management and alleviation of glacial lake explosion and flood hazards during the study period, and identify the vulnerable zone based on glacier changes. The Himalayan glaciers are losing rapidly due to global warming and climate change. This is alarming indication to the people and property living in downstream area of this country. It is highly recommended to count the amounts of water formed from snow melting for irrigation, power generation, and hydroelectricity. Influential attention must pay for the national disaster center for assessing the water control to stop floods and maintain a healthy amount of the reservoir. Comprehensive researches should be taken to adopt and mitigate the climate change and glacier monitoring. Both RS and field-based techniques are essential for comprehensive study of the glaciers, its changes and the impact to the people and property [3, 13-19, 32-34]. It is possible that this study may provide an access to in sequence for decision makers, scientists, and wide-ranging people at large in the area and afar. Comprehensive investigation of the causes of glacier cover changes, prediction of the changes and vulnerability study is our future work.

\section{Acknowledgment}

The authors would like to acknowledge Professor Raquib Ahmed, Department of Geography and Environmental Studies, Faculty of Life and Earth Science at University of Rajshahi, Bangladesh for his advice during conducting this study project.

\section{Author Contributions}

M.K. (Researcher) designed the research plan, accomplished its processes, and wrote the manuscript. I.M. (Assist. Prof.) reviewed the manuscript. A.M.F.Al-Q. (Professor) reviewed, edited, submitted the paper to the EER Journal, and is the corresponding author.

\section{References}

1. Gurung DR, Giriraj A, Aung KS, Shrestha B, Kulkarni AV. Snow-cover mapping and monitoring in the Hindu Kush-Himalayas. ICIMOD; 2011.

2. Rees WG. Remote sensing of snow and ice. CRC Press, Taylor \& Francis Group; 2006.

3. Mahagaonkar A, Wangchuk S, Ramanathan AL, Tshering D, Mahanta C. Glacier Environment and Climate Change in BhutanAn Overview. J. Clim. Change 2017;3:1-10.

4. Fadhil AM. Drought mapping using geo-information technology for some sites in the Iraqi Kurdistan region. Int. J. Digit. Earth 2011;4,3:239-257.

5. World Meteorological Organization (WMO). Space and climate change: Use of space-based technologies in the United Nations system; 2011.

6. Fadhil AM. Sand Dunes monitoring using remote sensing and GIS Techniques for some sites in Iraq. Proc. In: PIAGENG 2013: Intelligent Information, Control, and communication technology for agricultural engineering. 3rd International conference on photonics and Image in agriculture engineering; 19 March 2013; Sanya, China.

7. Wu W, Zucca C, Muhaimeed AS, et al. Soil Salinity prediction and mapping by machine learning regression in central Mesopotamia, Iraq. Land Degrad. Dev. 2018;29:4005-4014.

8. Bajracharya SR, Mool PK, Shrestha BR. Impact of climate change on Himalayan glaciers and glacial lakes: Case studies on GLOF and associated hazards in Nepal and Bhutan. ICIMOD; 2007. p. 3

9. Nolin AW, Stroeve J. The changing albedo of the Greenland Ice Sheet: Implications for climate modeling. Ann. Glaciol. 1997;25:51-57.

10. UNEP Global Environmental Alert Service-GEAS [Internet]. 2012. [Accessed on 30 Nov. 2018]. Available from: https://na. unep.net/geas/archive/pdfs/Oct_11_Amazon_Drought.pdf

11. Negi HS, Thakur NK, Snehmani G. Monitoring of Gangotri Glacier Using Remote Sensing and Ground Observations. J. Earth Syst. Sci. 2012;121,4:855-866.

12. Raup B. Remote sensing and GIS technology in the global land Ice measurements from Space, GLIMS Project. ELSIVIER; 2007.

13. Kulkarni AV. Mass balance of Himalayan glaciers using AAR and ELA methods. J. Glaciol. 1992;38:101-104.

14. Krishna AP. Satellite remote sensing applications for snow cover characterization in the morphogenetic regions of upper Tista River Basin, Sikkim Himalaya. Int. J. Remote Sens. 1996;17, 4:651-656.

15. Konig M, Winther JG, Isaksson E. Measuring snow and glacier properties from satellite. Rev. Geophys. 2001;39:1-27.

16. Kulkarni AV, Bahuguna IM. Glacial Retreat in the Baspa Basin, Himalayas, Monitored with Satellite stereo data. J. Glaciol. 2002;48,160:171-172.

17. Bolch T, Kamp U. Glacier mapping in high mountains using DEMs, Landsat and ASTER data. ${ }^{\text {th }}$ International Symposium on high mountain remote sensing cartography; 2006. p.37-48 Earth Surface Processes and Landforms 12.

18. Bahuguna IM, Kulkarni AV, Nayak S, Rathore BP, Negi HS, Mathur P. Himalayan glacier retreat using IRS 1C PAN stereo data. Int. J. Remote Sens. 2007;28,2:437-432.

19. Kulkarni AV. Effect of global warming on the Himalayan cryosphere Jalvigyan Sameeksha. 2007;22:93-108.

20. Veetil BK. A remote sensing approach for monitoring debris-covered glaciers in the high altitude Karakoram Himalayas. Int. J. Geomat. Geosci. 2012;2:833-841.

21. Global Land Cover Facility (GLCF), Maryland University. Available from: http://glcf.umd.edu/.

22. Global Visualization Viewer (GloVis), United States Geological Survey USGS. Available from: https://glovis.usgs.gov/.

23. Regional Database System, International center for integrated mountain development (ICIMOD). Available from: http://rds. icimod.org/

24. Ahmed B, Ahmed R. Modeling urban land cover growth dynam- 
ics using multi-yemporal satellite images: A case study of Dhaka, Bangladesh. ISPRS Int. J. Geo-Inf. 2012;1:3-31.

25. Eastman JR. IDRISI Taiga guide to GIS and image processing; Manual version 16.02; Clark Labs: Worcester, MA, USA; 2009.

26. Bajracharyaa SR, Maharjana SB, Shresthaa F, et.al. The glaciers of the Hindu Kush Himalayas: current status and observed changes from the 1980s to 2010. Int. J. Water Resour. Develop. 2015;31,2:161-173.

27. Haque MI, Basak R. Land cover change detection using GIS and remote sensing techniques: A spatio-temporal study on Tanguar Haor, Sunamganj, Bangladesh. Egypt. J. Remote Sens. Space Sci. 2017;20:251-263.

28. Shrestha F, Uddin K, Maharjan SB, Bajracharya SR. Application of remote sensing and GIS in environmental monitoring in the Hindu Kush Himalayan Region. AIMS Environ. Sci. 2016;3: 646-662.

29. Ross B, Walsh J. Synoptic-scale Influences of Snow Cover and Sea Ice. Mon. Weather Rev. 1986;114:1795-1810.
30. Maurer JM, Rupper SB, Schaefer JM. Quantifying ice loss in the Eastern Himalayas since 1974 using declassified spy satellite imagery. Cryosphere. 2016;10:2203.

31. Gurung J, Roshan MB. Climate change and glacial retreat in the Himalaya: Implication for soil and plant development. Kathmandu Univ. J. Sci. Eng. Technol. 2012;8:153-163.

32. Mool PK, Wangda D, Bajracharya SR, Kunzang K, Gurung DR, Joshi SP. Inventory of Glaciers, Glacial Lakes and Glacial Lake outburst Floods- Monitoring and Early Warning systems in the Hindu Kush-Himalayan region, Bhutan, Kathmandu, International centre for integrated mountain development (ICIMOD); 2001.p.227.

33. Belward AS, Valenzuela CR. Remote sensing and geographical information systems for resource management in developing countries, Springer; 1991 edition; 1991.p.506.

34. Armstrong RL, Brodzik MJ. Hemispheric-scale comparison and evaluation of passive-microwave snow algorithms. Ann. Glaciol. 2002;34:38-44. 